\title{
Comparative analysis of monotherapy versus duotherapy antiseizure drug management for postoperative seizure control in patients undergoing an awake craniotomy
}

\author{
Chikezie I. Eseonu, MD, ${ }^{1}$ Francisco Eguia, BA, ${ }^{1}$ Oscar Garcia, MPH, ${ }^{1}$ Peter W. Kaplan, MB, FRCP, ${ }^{2}$ \\ and Alfredo Quiñones-Hinojosa, MD'1
}

1Department of Neurological Surgery and Neuro-Oncology Outcomes Laboratory, Johns Hopkins University; and 'Department of Neurology, Johns Hopkins University School of Medicine, Baltimore, Maryland

\begin{abstract}
OBJECTIVE Postoperative seizures are a common complication in patients undergoing an awake craniotomy, given the cortical manipulation during tumor resection and the electrical cortical stimulation for brain mapping. However, little evidence exists about the efficacy of postoperative seizure prophylaxis. This study aims to determine the most appropriate antiseizure drug (ASD) management regimen following an awake craniotomy.

METHODS The authors performed a retrospective analysis of data pertaining to patients who underwent an awake craniotomy for brain tumor from 2007 to 2015 performed by a single surgeon. Patients were divided into 2 groups, those who received a single ASD (the monotherapy group) and those who received 2 types of ASDs (the duotherapy group). Patient demographics, symptoms, tumor characteristics, hospitalization details, and seizure outcome were evaluated. Multivariable logistic regression was used to evaluate numerous clinical variables associated with postoperative seizures.

RESULTS A total of 81 patients underwent an awake craniotomy for tumor resection of an eloquent brain lesion. Preoperative baseline characteristics were comparable between the 2 groups. The postoperative seizure rate was $21.7 \%$ in the monotherapy group and $5.7 \%$ in the duotherapy group $(p=0.044)$. Seizure outcome at 6 months' follow-up was assessed with the Engel classification scale. The duotherapy group had a significantly higher proportion of seizure-free (Engel Class I) patients than the monotherapy group ( $90 \%$ vs $60 \%, p=0.027$ ). The length of stay was similar, 4.02 days in the monotherapy group and 4.51 days in the duotherapy group $(p=0.193)$. The 90 -day readmission rate was higher for the monotherapy group ( $26.1 \%$ vs $8.5 \%$ in the duotherapy group, $p=0.044$ ). Multivariate logistic regression showed that preoperative seizure history was a significant predictor for postoperative seizures following an awake craniotomy (OR 2.08, 95\% Cl 0.56-0.90, p<0.001).

CONCLUSIONS Patients with a preoperative seizure history may be at a higher risk for postoperative seizures following an awake craniotomy and may benefit from better postoperative seizure control with postoperative ASD duotherapy.

https://thejns.org/doi/abs/10.3171/2017.1.JNS162913
\end{abstract}

KEY WORDS awake craniotomy; seizures; antiepileptics; monotherapy; polytherapy; epilepsy; oncology

$\mathrm{P}$ OSTOPERATIVE seizures occur in $17 \%-50 \%$ of patients who have a craniotomy for a brain tumor, depending on the tumor type, size, and location. . $^{3,67,13}$, 16,19,24,44 These risks for perioperative seizures can increase following an awake craniotomy for tumor resection, where in addition to cortical manipulation to remove the tumor, eloquent regions of the brain undergo electrical stimulation for cortical mapping. ${ }^{18,38,42}$ Seizures following a craniotomy can lead to increased intracranial pressure, neurological decline, cerebral hemorrhage, or hypoxia. ${ }^{27,28,30}$
From the patient's perspective, these complications can lead to longer hospitalizations, increased hospital costs, permanent morbidity, and diminished quality of life and have a negative effect on survival., 917,33

Antiseizure drugs (ASDs) following an awake craniotomy are important for the management of postoperative seizures, although there is varying evidence about their efficacy. ${ }^{16,19,26,28-30,34,43}$ Following cortical stimulation and tumor resection in an awake surgery, ASD management must be carefully handled. Inadequate ASD use may lead 
to postoperative seizures, while overuse of ASDs may result in detrimental drug-related side effects..$^{51}$ In addition, excessive ASD use can present additional costs to a patient. ${ }^{1}$ As health care reimbursement focuses increasingly on postoperative morbidity and efficiency of care, it is important to determine the optimal postoperative management for seizure prophylaxis and treatment following an awake craniotomy. ${ }^{39}$ Despite the evolution of ASDs and growing knowledge about tumor-related seizures, the optimal use of ASDs for postoperative seizure prophylaxis after an awake craniotomy remains unclear, as there are no evidence-based guidelines for their use in this setting..$^{40,41}$

In this paper, we aim to evaluate the efficacy of postoperative monotherapy and duotherapy of ASD regimens for postoperative seizure treatment following an awake craniotomy, to determine whether combinations of ASDs play a role in improved prevention of seizures after an awake craniotomy.

\section{Methods}

This study was approved by the Johns Hopkins institutional review board.

\section{Patient Selection}

A retrospective data analysis was conducted on 81 cases in which patients underwent an awake craniotomy for an eloquent intracranial lesion, or lesions involving areas of the brain that control speech, sensory, or motor function, between April 2007 and February 2016 and performed by a single surgeon (A.Q.-H.). Patients who received a single ASD for postoperative seizure prophylaxis or treatment were considered the monotherapy group, while patients who received 2 ASDs postoperatively were considered the duotherapy group. Patients who had a preoperative seizure history of 3 or more seizure events per month were selected to receive postoperative duotherapy, while patients with a preoperative seizure history of fewer than 3 events per month received monotherapy. All patients were either on ASD monotherapy preoperatively, or were given a single dose of an ASD (monotherapy) before surgery. Postoperative levetiracetam was dosed at 500-1500 mg every 12 hours, and postoperative phenytoin was started at $100 \mathrm{mg}$ every 8 hours. Phenytoin serum levels were checked daily, and dosing was adjusted to obtain a normal serum level.

\section{Postoperative Evaluation}

All patients were evaluated for postoperative complications immediately after surgery, at the 1-month followup visit, and 6 months following surgery in an outpatient clinic. The Engel classification system was used to evaluate seizure outcome following surgery. The outcome was considered Class I if the patient was seizure free; Class II if he or she had rare seizures, less than 3 over the 6-month span; Class III if the patient had some improvement, with more than 3 seizures over the 6-month course; and Class IV if there was no improvement, with no reduction of seizures and possible worsening. Seizures were diagnosed by observation, clinical examination, or electroencephalography. The length of hospitalization was considered to be the period from the day of surgery until the day of discharge.

\section{Tumor Volumetrics}

The preoperative tumor volume was determined using either T1-weighted MRI with contrast or T2-weighted MRI (1.5- to 3-mm axial cuts) in addition to fluid-attenuated inversion recovery (FLAIR) axial cuts. The OsiriX software (Pixmeo) was used to determine the tumor volume by a clinician blinded to the cohorts, as we have previously described., ${ }^{4,514,15}$ The postoperative tumor volume was calculated using the MR images that were obtained 48 hours after surgery using the previously described methods. The extent of resection was calculated based on the formula (preoperative tumor volume - postoperative tumor volume)/preoperative tumor volume.

\section{Statistical Analysis}

Descriptive statistics were reported as numbers and percentages for categorical variables and means and standard deviations for continuous parametric variables. Parametric comparisons between 2 groups were performed using the 2-sample t-test, and nonparametric comparisons were performed using a rank-sum test. Categorical comparisons between the 2 groups (monotherapy vs duotherapy) were performed using Pearson's chi-square test. Associations with postoperative seizures were analyzed using logistic regression. The significance of differences was evaluated according to a Type I error-rate threshold of $\alpha=0.05$. For the postoperative seizure risk factors, variables that had a $\mathrm{p}$ value $<0.1$ on the univariate analysis were entered into a multivariate logistic regression analysis. A biostatistician contributed to the statistical analysis of this study (O.G.). All statistical analyses were done using STATA 14.

\section{Results}

\section{Patient Population}

Between January 2007 and February 2016, 81 patients with a supratentorial eloquent brain lesion underwent an awake craniotomy for the first time. All patients were given an ASD prior to surgery. Following surgery, 46 patients were treated with a single ASD (the monotherapy group). The other 35 patients were treated with 2 ASDs (the duotherapy group). All patients in the monotherapy group were treated with levetiracetam postoperatively. In the duotherapy group, 30 patients received levetiracetam with phenytoin as their postoperative duotherapy; 5 patients had a history of prior adverse reactions to phenytoin and were placed on an alternative duotherapy (3 patients had levetiracetam with valproic acid, and 2 patients had levetiracetam with lacosamide). The mean age was 49.1 years in the monotherapy group and 44.3 years in the duotherapy group $(p=0.162)$. Tumors involved the motor or sensory cortex, respectively, in $39.1 \%$ and $13.1 \%$ of the monotherapy group and $57.1 \%(\mathrm{p}=0.108)$ and $14.3 \%$ $(\mathrm{p}=0.872)$ of the duotherapy group. Tumors involved the language cortex in $47.8 \%$ of the monotherapy group and $28.6 \%$ of the duotherapy group $(\mathrm{p}=0.079)$. Glioma pathology accounted for $86.9 \%$ of tumors in the monotherapy group and $88.5 \%$ of those in the duotherapy group ( $\mathrm{p}=$ 0.827 ). Additional tumor pathology and location comparisons were found to be similar between the 2 groups and are reported in Table 1. 
The mean preoperative tumor volume was $45.3 \mathrm{~cm}^{3}$ and $52.5 \mathrm{~cm}^{3}$ in the monotherapy and duotherapy groups, respectively $(\mathrm{p}=0.253)$. The mean postoperative tumor volume was $9.7 \mathrm{~cm}^{3}$ in the monotherapy group and $8.2 \mathrm{~cm}^{3}$ in the duotherapy group $(p=0.762)$. The mean extent of resection was $81.5 \%$ in the monotherapy group and $80.7 \%$ in the duotherapy group $(\mathrm{p}=0.923)$.

\section{Clinical Presentation}

Preoperative seizures were present in $54 \%$ of the patients in the monotherapy group, and these patients had an average rate of 1.2 seizures per month prior to surgery. In the duotherapy group, $57.1 \%$ of patients had preoperative seizures $(p=0.523)$, with an average rate of 3.4 seizures per month $(\mathrm{p}<0.001)$. The presentation of headache was found in $23.9 \%$ of the monotherapy cohort and $17.1 \%$ of the duotherapy group $(\mathrm{p}=0.459)$. Focal motor/sensory deficits were present preoperatively in $10.9 \%$ of the patients in the monotherapy group and $12.2 \%$ of those in the duotherapy group, respectively $(\mathrm{p}=0.383)$. Language deficits were seen in $37 \%$ of the monotherapy group and $42.9 \%$ of the duotherapy group $(\mathrm{p}=0.590)$.

\section{Postoperative Outcomes}

The mean length of hospitalization was 4.02 days for the monotherapy group and 4.51 days for the duotherapy group $(\mathrm{p}=0.193)$. Readmission to the hospital within 90 days of surgery occurred in $26.1 \%$ of the monotherapy group and $8.5 \%$ of the duotherapy $(\mathrm{p}=0.044)$. The most common reasons for readmission for the 12 monotherapy patients were: seizures in 7 patients (58.3\%), worsening aphasia in 2 patients $(16.7 \%)$, altered mental status in 2 patients $(16.7 \%)$, and sensory/motor changes in 1 patient (8.3\%). Of the 12 monotherapy readmissions, EEG findings of seizure activity were found in 6 of the patients presenting with seizure, while 1 patient was observed to have seizure activity by a clinician. For the 3 duotherapy group readmissions, seizures were the most common cause for readmission, occurring in 2 patients $(66.6 \%)$, followed by altered mental status, occurring in 1 patient (33.3\%). For the 3 duotherapy readmissions, 1 patient had EEG findings of seizure activity and 1 was observed to have seizure activity by a clinician.

At the 6 months' follow-up, postoperative seizures had occurred in $21.7 \%$ of the patients treated with monotherapy and $5.7 \%$ of those treated with duotherapy $(\mathrm{p}=0.044)$. In the monotherapy patients, 8 patients had postoperative seizures confirmed by EEG, 1 patient had seizure activity observed by a clinician, and 1 patient had family-reported seizure activity. In the duotherapy group, 1 patient had postoperative seizures confirmed by EEG and 1 patient had seizure activity observed by a clinician. For patients who had seizures after surgery, the average rate of postoperative seizures was 1.1 times per month in the monotherapy cohort and 1.0 times per month in the duotherapy cohort $(\mathrm{p}=0.343)$. With respect to the patients with no preoperative seizure history (21 in the monotherapy group and 15 in the duotherapy group), there were no postoperative seizures seen within the 6 months following surgery in either cohort. Among the patients given postoperative
TABLE 1. Demographic and clinical characteristics of 81 patients who underwent an awake craniotomy for a brain lesion

\begin{tabular}{|c|c|c|c|}
\hline \multirow[b]{2}{*}{ Characteristic } & \multicolumn{2}{|c|}{ Group } & \multirow[b]{2}{*}{$\begin{array}{c}p \\
\text { Value }\end{array}$} \\
\hline & $\begin{array}{l}\text { Monotherapy } \\
(n=46)\end{array}$ & $\begin{array}{l}\text { Duotherapy } \\
\qquad(n=35)\end{array}$ & \\
\hline Age, mean (SD) & $49.1(15.7)$ & $44.3(14.3)$ & 0.162 \\
\hline Sex & & & 0.099 \\
\hline Male & $26(56.5)$ & $26(74.3)$ & \\
\hline Female & $20(43.5)$ & $9(25.7)$ & \\
\hline KPS, mean (SD) & $95.0(6.62)$ & $93.4(9.38)$ & 0.157 \\
\hline \multicolumn{4}{|l|}{ Tumor location } \\
\hline Language cortex & $22(47.8)$ & $10(28.6)$ & 0.079 \\
\hline Motor cortex & $18(39.1)$ & $20(57.1)$ & 0.108 \\
\hline Primary sensory cortex & $6(13.1)$ & $5(14.3)$ & 0.872 \\
\hline Side & & & 0.343 \\
\hline Left & $37(80.4)$ & $25(71.4)$ & \\
\hline Right & $9(19.6)$ & $10(28.6)$ & \\
\hline Pathology & & & 0.399 \\
\hline Grade II glioma & $16(34.8)$ & $11(31.4)$ & \\
\hline Grade III glioma & $6(13.0)$ & $11(31.4)$ & \\
\hline Grade IV glioma & 18 (39.1) & $9(25.7)$ & \\
\hline Metastasis & $1(2.2)$ & $1(2.9)$ & \\
\hline Cavernoma & $4(8.7)$ & $3(8.6)$ & \\
\hline Abscess & $1(2.2)$ & $0(0.0)$ & \\
\hline \multicolumn{4}{|l|}{ Tumor vol \& EOR, mean (SD) } \\
\hline Preop tumor vol, $\mathrm{cm}^{3}$ & $45.3(39.3)$ & $52.5(44.6)$ & 0.253 \\
\hline Postop tumor vol, $\mathrm{cm}^{3}$ & $9.7(18.9)$ & $8.2(9.9)$ & 0.762 \\
\hline EOR, \% & $81.5(2.5)$ & $80.7(2.5)$ & 0.923 \\
\hline Preop seizures & $25(54.0)$ & $20(57.1)$ & 0.523 \\
\hline Focal & $10(21.7)$ & $8(22.9)$ & 0.905 \\
\hline Generalized & $15(32.6)$ & $12(34.3)$ & 0.874 \\
\hline Average per mo, (SD)* & $1.2(0.7)$ & $3.4(1.9)$ & $<0.001$ \\
\hline Intraop seizure & $2(4.3)$ & $2(5.7)$ & 0.779 \\
\hline Postop seizures & $10(21.7)$ & $2(5.7)$ & 0.044 \\
\hline Average per mo, (SD)* & $1.1(0.3)$ & $1.0(0)$ & 0.343 \\
\hline LOS, mean (SD) & $4.02(3.95)$ & $4.51(8.96)$ & 0.193 \\
\hline 90-day readmission & $12(26.1)$ & $3(8.5)$ & 0.044 \\
\hline
\end{tabular}

$E O R=$ extent of resection; LOS = length of stay.

Data are numbers of patients (\%) unless otherwise indicated. Boldface type indicates statistical significance.

* Average number of seizures per month for patients who had seizures during the specified time period.

seizure prophylaxis with no prior preoperative seizure history, the mean duration of postoperative ASD treatment was 7.0 days in the monotherapy group and 9.3 days in the duotherapy group $(\mathrm{p}=0.412)$. From the overall cohort, 69 patients (85.2\%) had no postoperative seizures: 36 in the monotherapy group (78.2\%) and 33 in the duotherapy group $(94.3 \%, \mathrm{p}=0.044)$.

Evaluation at 6 months' follow-up, based on the Engel classification, showed that for the monotherapy and duotherapy cohorts, respectively, that outcomes were classified as Engel I (60\% vs 90\%), Engel II (4\% vs 10\%), Engel 
TABLE 2. Distribution of postoperative AED treatment type and outcomes at 6-month postoperative follow-up for patients who had preoperative seizures

\begin{tabular}{lccccc}
\hline \multirow{2}{*}{$\begin{array}{c}\text { Type of Postop } \\
\text { AED Tx }\end{array}$} & \multicolumn{4}{c}{ Engel Class at 6-Mo Follow-Up } & \multirow{2}{*}{$\begin{array}{c}p \\
\text { Value }\end{array}$} \\
\cline { 2 - 5 } $\begin{array}{c}\text { Monotherapy } \\
(n=25)\end{array}$ & $15(60.0 \%)$ & $1(4.0 \%)$ & $7(28.0 \%)$ & $2(8.0 \%)$ & \\
$\begin{array}{l}\text { Duotherapy (n } \\
=20)\end{array}$ & $18(90.0 \%)$ & $2(10.0 \%)$ & $0(0.0 \%)$ & $0(0.0 \%)$ & \\
\hline Total & $33(73.3 \%)$ & $3(6.7 \%)$ & $7(15.6 \%)$ & $2(4.4 \%)$ & 0.027 \\
\hline
\end{tabular}

Engel I = seizure free; Engel II = rare seizures; Engel III = worthwhile improvement; Engel IV = no worthwhile improvement; $\mathrm{Tx}=$ treatment.

The duotherapy cohort had a significantly greater percentage of patients with Engel Class I outcomes at the postoperative follow-up visit. Boldface type indicates statistical significance.

III ( $28 \%$ vs $0 \%)$, and Engel IV (8\% vs $0 \%),(\mathrm{p}=0.027$, Table 2).

Multivariate logistic regression demonstrated that patients with a preoperative history of seizures were more likely to have seizures following their awake craniotomy (OR 2.08 [95\% CI 1.74-2.47], $\mathrm{p}<0.001$ ). Postoperative seizures in this study cohort were not found to be influenced by preoperative Karnofsky Performance Status (KPS), intraoperative seizures, tumor volume, tumor grade, extent of resection, type of ASD used, or tumor location (Table 3).

\section{Discussion}

Postoperative seizures following an awake craniotomy present a challenging complication that requires a good understanding about ASD management. In addition to the intraoperative cortical irritation, cerebral hypoxia, and hemorrhages that have been associated with causing seizures following a craniotomy, an awake craniotomy adds cortical electrical stimulation to map out eloquent regions of the brain, and this can also cause seizures..$^{30,45,46}$ Intracranial pressure changes and brain shifts following surgery can also lower seizure thresholds, with the highest incidence of postoperative seizures found in the initial 48-72 hours after surgery. ${ }^{30,32,50}$ Our study shows that for patients who undergo an awake craniotomy and have a preoperative seizure history, postoperative ASD duotherapy can decrease the risk of seizures after the operation and reduce hospital readmissions compared with monotherapy treatment. We also show that a preoperative history of seizure is a significant predictor for seizures following an awake craniotomy.

\section{Length of Hospitalization and Readmission}

Postoperative seizures following brain tumor surgery have been shown to be associated with longer hospital stays and a higher likelihood of having a hospital readmission. ${ }^{11,35}$ In our study, we found that the length of stay was similar between the 2 cohorts, but that the monotherapy group had a higher rate of readmissions. The length of stay was slightly greater than 4 days for both of our cohorts likely due to the fact that observation in an inpatient set-
TABLE 3. Logistic regression for postoperative seizures for 81 patients undergoing an awake craniotomy for a brain lesion

\begin{tabular}{|c|c|c|c|c|}
\hline \multirow[b]{2}{*}{ Covariates } & \multicolumn{2}{|c|}{ Univariate Analysis } & \multicolumn{2}{|c|}{ Multivariate Analysis } \\
\hline & OR (95\% Cl) & $\begin{array}{c}p \\
\text { Value }\end{array}$ & OR $(95 \% \mathrm{Cl})$ & $\begin{array}{c}p \\
\text { Value }\end{array}$ \\
\hline $\begin{array}{l}\text { Preop KPS } \\
\text { score }\end{array}$ & $0.99(0.97-1.01)$ & 0.112 & & NA \\
\hline Preop seizure & $1.31(1.06-1.78)$ & 0.046 & $2.08(1.74-2.47)$ & $<0.001$ \\
\hline Intraop seizure & $1.21(0.88-1.65)$ & 0.236 & & NA \\
\hline Preop tumor vol & $1.01(1.00-1.02)$ & 0.017 & & NS \\
\hline $\begin{array}{l}\text { Postop tumor } \\
\text { vol }\end{array}$ & $1.02(1.00-1.03)$ & 0.034 & & NS \\
\hline EOR & $0.78(0.48-1.28)$ & 0.316 & & NA \\
\hline Grade II glioma & $0.78(0.59-1.02)$ & 0.065 & & NS \\
\hline $\begin{array}{l}\text { Grade III/IV } \\
\text { glioma }\end{array}$ & $1.29(0.98-1.69)$ & 0.164 & & NA \\
\hline Levetiracetam & $0.95(0.61-1.47)$ & 0.798 & & NA \\
\hline Phenytoin & $1.08(0.80-1.45)$ & 0.606 & & NA \\
\hline Motor cortex & $1.05(0.78-1.42)$ & 0.731 & & NA \\
\hline Sensory cortex & $1.04(0.74-1.47)$ & 0.806 & & NA \\
\hline $\begin{array}{l}\text { Language } \\
\text { cortex }\end{array}$ & $1.11(0.78-1.58)$ & 0.540 & & NA \\
\hline
\end{tabular}

NA = not applicable; NS = not statistically significant.

Preoperative seizures were found to be a significant predictor for postoperative seizures following an awake craniotomy.

ting is often longer for patients who sustain a postoperative seizure. Often, following a postoperative ictal event, the patient requires neuroimaging, an electroencephalogram, and a neurology consultation. These measures can lengthen hospitalization and increase the hospital costs. ${ }^{15}$

Already, Medicare and Medicaid have implemented financial penalties for readmissions that are related to preventable morbidity. ${ }^{39}$ In addition, the Affordable Care Act makes hospitals and surgeons accountable for patient care costs that are deemed to be avoidable. ${ }^{39}$ Dewan et al. ${ }^{11}$ found that patients with glioma surgery who had a postoperative seizure presented to the emergency department twice as often as those who did not (44\% vs $19 \%)$. In our cohort, we found that following an awake craniotomy, patients who had a postoperative seizure and were treated with ASD monotherapy were 3 times as likely to require readmission as those who were treated with duotherapy (26\% vs $8 \%$ ). Given that our patient population all had surgery involving the eloquent language or sensorimotor regions of the brain, any type of surgical site inflammation or irritation would often elicit a seizure or noticeable symptom (i.e., aphasia/weakness) that would prompt the patient to go to the emergency department, where our institution often admits the patient for observation.

Dickinson et al. ${ }^{12}$ reported that readmissions following brain tumor surgery often were caused by neurological symptoms that accounted for one-third (37\%) of readmissions; the next most common reason for readmission in their study was infection (29\%). We found that seizures were the most common reason for readmissions in our 
patient cohort, accounting for nearly two-thirds of readmissions $(58 \%$ in the monotherapy group and $66 \%$ in the duotherapy group). In contrast to the study by Dickinson et al., in our study, all of the patients who were readmitted had a preoperative seizure history; moreover, nearly half of our cohort (47\%) had tumors near or involving the perirolandic motor region, which has been associated with higher perioperative seizure occurrence. ${ }^{14,22,38}$

\section{ASD Use}

The literature has presented conflicting evidence regarding the efficacy of prophylactic ASD therapy, with some authors favoring ASD use $\mathrm{e}^{26,34,43}$ and others against it. ${ }^{19,28,30}$ Despite the varying claims, most neurosurgeons use ASDs for seizure prophylaxis following a craniotomy. ${ }^{33}$ Notable support for postoperative ASD use after a craniotomy include a randomized control trial by North et al., ${ }^{37}$ which showed that there was a significant reduction of postoperative seizures following a craniotomy using phenytoin for seizure prophylaxis. A retrospective analysis by Zachenhofer et al. ${ }^{50}$ found that prophylaxis with levetiracetam also lowered seizure risk after a craniotomy for brain tumor. Conversely, Wu et al. ${ }^{48}$ conducted a randomized controlled trial involving patients undergoing craniotomies for intraaxial brain tumors that did not show any difference in postoperative seizure occurrence with prophylaxis using phenytoin.

Early studies often used phenytoin to evaluate the efficacy of ASDs for seizure prophylaxis. The rate of adverse effects with phenytoin has been approximated at $15 \%$. In addition, phenytoin also affects the metabolism of other medications, including chemotherapeutic drugs., $9,36,49,50$ Levetiracetam has been shown to have fewer side effects than phenytoin, with somnolence being the most common side effect. The reported rate of adverse effects for levetiracetam ranges from $5 \%$ to $27 \%$, and it has no effect on the metabolism of other drugs. ${ }^{20,21,50}$ Our institution uses levetiracetam more than other ASDs following craniotomy. Studies have shown postoperative seizures rates of $1 \%-12 \%$ with the use of levetiracetam monotherapy for patients who have undergone surgical treatment of supratentorial lesions, but we have previously reported higher seizure activity in patients with perirolandic eloquent region tumors, ${ }^{14}$ which could explain our higher incidence of postoperative seizures in the monotherapy group (21\%), in which nearly $40 \%$ of the patients had perirolandic lesions. ${ }^{2,20,35}$

\section{Duotherapy}

For seizure management in general, monotherapy is used for newly diagnosed seizures, while duotherapy is considered if there is a failure of the monotherapy treatment. ${ }^{25}$ In this study, we found improved postoperative seizure prophylaxis with the use of duotherapy compared with monotherapy for our patient population. This observation is likely due to the varying mechanisms of action of the 2 ASDs, as well as possible synergistic effects. The potential benefit of a synergistic effect from a combination of ASDs must be weighed against toxicity and unwarranted drug interactions. ${ }^{31}$ Since ASDs affect multiple ion channels and neurotransmitters, it is difficult to determine what mechanism is responsible for the drugs' synergy. The mechanism of action for levetiracetam involves binding the synaptic vesicle protein 2A (SV2A), which provides a unique pathway that can improve the effect of other ASDs that target traditional mechanisms of augmenting the GABAergic or glutamatergic neurotransmission as well as those inhibiting sodium channels. ${ }^{25}$ We tend to use levetiracetam and phenytoin as our combination of choice, given their different mechanisms of actions (phenytoin inhibits sodium channels), although future studies are warranted to look at other combinations of ASD use as well as the use of duotherapy for asleep craniotomies for brain tumor resection. Our general practice is to use postoperative duotherapy for patients who had a high frequency of preoperative seizures ( $\geq 3$ or more per month). We did not find many side effects from our postoperative ASD use in either cohort. During the 6-month follow-up period, levetiracetam was discontinued prematurely due to complaints of lethargy in 1 patient in the monotherapy group (2.2\%) and lacosamide was prescribed instead. In the duotherapy group, the drug combination was switched from levetiracetam and phenytoin to levetiracetam and lacosamide in 2 patients $(5.7 \%)$ because of delirium in 1 case and thrombocytopenia in the other $(\mathrm{p}=0.403)$.

\section{Duration of ASD Use}

In addition to the number of postoperative ASDs prescribed, the duration of postoperative ASD prophylaxis also varies from surgeon to surgeon, with 7 days often being the duration of prophylactic treatment for patients with no preoperative seizure history. ${ }^{10}$ Although prophylactic ASD treatment is used in the postoperative period to avoid complications of seizure, its efficacy in patients without a seizure history is uncertain in the literature. ${ }^{16,47}$ In a survey of members of the AANS/CNS Section on Tumors, 21\% of neurosurgeon respondents reported using postoperative ASDs for $\leq 7$ days, $35 \%$ for 2-6 weeks, and $36 \%$ for $>6$ weeks. ${ }^{10}$ In our cohort, patients who had no preoperative seizure history were maintained, respectively, on postoperative monotherapy for 7.0 days and duotherapy for 9.3 days. Patients with a history of preoperative seizures or those who had postoperative seizures were maintained on monotherapy or duotherapy with the assistance of a neurology team, who determined the duration of the therapy.

\section{Postoperative Seizure Predictors}

In addition to the use of combination therapy, it is helpful to determine what other factors may influence the incidence of postoperative seizures following an awake craniotomy. Awake craniotomy is frequently performed in patients undergoing resection of lesions involving the perirolandic region of the brain, given the sensorimotor function in the area, and surgical treatment of lesions in this area been shown to increase the incidence of perioperative seizures. ${ }^{42}$ In our study, $47 \%$ of our patients had lesions involving the perirolandic region. Pathology and tumor location are also believed to influence the chance for seizure occurrence. ${ }^{23}$ Preoperative seizures and lowgrade gliomas have also been shown to increase the risk of postoperative seizures in patients undergoing craniotomy. ${ }^{23,24,35-37}$ Chang et al. ${ }^{8}$ reported that postoperative 
seizures are less likely to be found in patients in whom gross-total resection was achieved. In our evaluation of perioperative factors that may influence the incidence of postoperative seizures, we found that preoperative seizure history had a significant association with postoperative seizures in our multivariate analysis. Although tumor volume and low-grade gliomas had a significant association with postoperative seizure in the univariate analysis, they were not found to be significant in the multivariate analysis. Given this information, duotherapy may benefit patients with a preoperative seizure history, who could be at a higher risk for postoperative seizures.

\section{Limits of the Study}

This study has limits that are inherent to retrospective studies. The Engel classification has previously been used for seizure analysis following tumor surgery; ${ }^{24}$ however, in our study, the preoperative seizure frequency was lower in the monotherapy group than in the duotherapy group, which would make it harder to demonstrate postoperative improvement regarding seizure frequency in the former group. Because the duotherapy cohort had a higher preoperative frequency of seizures, reductions could be expected to be more noticeable. In addition, our reporting of postoperative seizures was derived from documented diagnosis based on observation, clinical examination, or electroencephalography, which may have increased the incidence of seizures found in our cohort.

\section{Conclusions}

An awake craniotomy is a complex procedure performed for the resection of tumors in eloquent regions of the brain, and it requires an intricate understanding of postoperative seizure management for these patients. Our study suggests that patients with a preoperative seizure history may be at a higher risk for postoperative seizures following an awake craniotomy and may benefit from reduced postoperative seizures with the use of ASD duotherapy.

\section{References}

1. Allers K, Essue BM, Hackett ML, Muhunthan J, Anderson CS, Pickles K, et al: The economic impact of epilepsy: a systematic review. BMC Neurol 15:245, 2015

2. Bähr O, Hermisson M, Rona S, Rieger J, Nussbaum S, Körtvelyessy $\mathrm{P}$, et al: Intravenous and oral levetiracetam in patients with a suspected primary brain tumor and symptomatic seizures undergoing neurosurgery: the HELLO trial. Acta Neurochir (Wien) 154:229-235, 2012

3. Chaichana KL, Halthore AN, Parker SL, Olivi A, Weingart $\mathrm{JD}$, Brem $\mathrm{H}$, et al: Factors involved in maintaining prolonged functional independence following supratentorial glioblastoma resection. Clinical article. J Neurosurg 114:604-612, 2011

4. Chaichana KL, Jusue-Torres I, Lemos AM, Gokaslan A, Cabrera-Aldana EE, Ashary A, et al: The butterfly effect on glioblastoma: is volumetric extent of resection more effective than biopsy for these tumors? J Neurooncol 120:625-634, 2014

5. Chaichana KL, Jusue-Torres I, Navarro-Ramirez R, Raza SM, Pascual-Gallego M, Ibrahim A, et al: Establishing percent resection and residual volume thresholds affecting survival and recurrence for patients with newly diagnosed intracranial glioblastoma. Neuro-oncol 16:113-122, 2014

6. Chaichana KL, Parker SL, Olivi A, Quiñones-Hinojosa A: Long-term seizure outcomes in adult patients undergoing primary resection of malignant brain astrocytomas. Clinical article. J Neurosurg 111:282-292, 2009

7. Chaichana KL, Pendleton C, Zaidi H, Olivi A, Weingart JD, Gallia GL, et al: Seizure control for patients undergoing meningioma surgery. World Neurosurg 79:515-524, 2013

8. Chang EF, Potts MB, Keles GE, Lamborn KR, Chang SM, Barbaro NM, et al: Seizure characteristics and control following resection in 332 patients with low-grade gliomas. J Neurosurg 108:227-235, 2008

9. Deutschman CS, Haines SJ: Anticonvulsant prophylaxis in neurological surgery. Neurosurgery 17:510-517, 1985

10. Dewan MC, Thompson RC, Kalkanis SN, Barker FG II, Hadjipanayis CG: Prophylactic antiepileptic drug administration following brain tumor resection: results of a recent AANS/ CNS Section on Tumors survey. J Neurosurg [epub ahead of print June 24, 2016. DOI: 10.3171/2016.4.JNS16245]

11. Dewan MC, White-Dzuro GA, Brinson PR, Thompson RC, Chambless LB: Perioperative seizure in patients with glioma is associated with longer hospitalization, higher readmission, and decreased overall survival. J Neurosurg 125:1033-1041, 2016

12. Dickinson H, Carico C, Nuño M, Mukherjee D, Ortega A, Black KL, et al: Unplanned readmissions and survival following brain tumor surgery. J Neurosurg 122:61-68, 2015

13. Drappatz J, Schiff D, Kesari S, Norden AD, Wen PY: Medical management of brain tumor patients. Neurol Clin 25:1035-1071, ix, 2007

14. Eseonu CI, Rincon-Torroella J, ReFaey K, Lee YM, Nangiana J, Vivas-Buitrago T, et al: Awake craniotomy versus craniotomy under general anesthesia for perirolandic gliomas: Evaluating perioperative complications and extent of resection. Neurosurgery [epub ahead of print], 2017

15. Eseonu CI, Rincon-Torroella J, ReFaey K, Quinones-Hinojosa A: The cost of brain surgery: awake versus asleep craniotomy for perirolandic region tumors. Neurosurgery [epub ahead of print], 2017

16. Forsyth PA, Weaver S, Fulton D, Brasher PM, Sutherland G, Stewart D, et al: Prophylactic anticonvulsants in patients with brain tumour. Can J Neurol Sci 30:106-112, 2003

17. Foy PM, Copeland GP, Shaw MD: The natural history of postoperative seizures. Acta Neurochir (Wien) 57:15-22, 1981

18. Ghazanwy M, Chakrabarti R, Tewari A, Sinha A: Awake craniotomy: A qualitative review and future challenges. Saudi J Anaesth 8:529-539, 2014

19. Glantz MJ, Cole BF, Forsyth PA, Recht LD, Wen PY, Chamberlain MC, et al: Practice parameter: anticonvulsant prophylaxis in patients with newly diagnosed brain tumors. Report of the Quality Standards Subcommittee of the American Academy of Neurology. Neurology 54:1886-1893, 2000

20. Gokhale S, Khan SA, Agrawal A, Friedman AH, McDonagh DL: Levetiracetam seizure prophylaxis in craniotomy patients at high risk for postoperative seizures. Asian J Neurosurg 8:169-173, 2013

21. Goldberg-Stern H, Feldman L, Eidlitz-Markus T, Kramer U, Perez S, Pollak L, et al: Levetiracetam in children, adolescents and young adults with intractable epilepsy: efficacy, tolerability and effect on electroencephalogram--a pilot study. Eur J Paediatr Neurol 17:248-253, 2013

22. Gonen T, Grossman R, Sitt R, Nossek E, Yanaki R, Cagnano E, et al: Tumor location and IDH1 mutation may predict intraoperative seizures during awake craniotomy. J Neurosurg 121:1133-1138, 2014

23. Hwang SL, Lin CL, Lee KS, Lieu AS, Kuo TH, Chang CZ, et al: Factors influencing seizures in adult patients with 
supratentorial astrocytic tumors. Acta Neurochir (Wien) 146:589-594, 2004

24. Kahlenberg CA, Fadul CE, Roberts DW, Thadani VM, Bujarski KA, Scott RC, et al: Seizure prognosis of patients with low-grade tumors. Seizure 21:540-545, 2012

25. Kaminski RM, Matagne A, Patsalos PN, Klitgaard H: Benefit of combination therapy in epilepsy: a review of the preclinical evidence with levetiracetam. Epilepsia 50:387-397, 2009

26. Kern K, Schebesch KM, Schlaier J, Hansen E, Feigl GC, Brawanski AT, et al: Levetiracetam compared to phenytoin for the prevention of postoperative seizures after craniotomy for intracranial tumours in patients without epilepsy. J Clin Neurosci 19:99-100, 2012

27. Klimek M, Dammers R: Antiepileptic drug therapy in the perioperative course of neurosurgical patients. Curr Opin Anaesthesiol 23:564-567, 2010

28. Komotar RJ, Raper DM, Starke RM, Iorgulescu JB, Gutin PH: Prophylactic antiepileptic drug therapy in patients undergoing supratentorial meningioma resection: a systematic analysis of efficacy. J Neurosurg 115:483-490, 2011

29. Kong X, Guan J, Yang Y, Li Y, Ma W, Wang R: A metaanalysis: Do prophylactic antiepileptic drugs in patients with brain tumors decrease the incidence of seizures? Clin Neurol Neurosurg 134:98-103, 2015

30. Kuijlen JM, Teernstra OP, Kessels AG, Herpers MJ, Beuls EA: Effectiveness of antiepileptic prophylaxis used with supratentorial craniotomies: a meta-analysis. Seizure 5:291298, 1996

31. Kwan P, Brodie MJ: Combination therapy in epilepsy: when and what to use. Drugs 66:1817-1829, 2006

32. Lee ST, Lui TN, Chang CN, Cheng WC, Wang DJ, Heimburger RF, et al: Prophylactic anticonvulsants for prevention of immediate and early postcraniotomy seizures. Surg Neurol 31:361-364, 1989

33. Manaka S, Ishijima B, Mayanagi Y: Postoperative seizures: epidemiology, pathology, and prophylaxis. Neurol Med Chir (Tokyo) 43:589-600, discussion 600, 2003

34. Merrell RT, Anderson SK, Meyer FB, Lachance DH: Seizures in patients with glioma treated with phenytoin and levetiracetam. J Neurosurg 113:1176-1181, 2010

35. Milligan TA, Hurwitz S, Bromfield EB: Efficacy and tolerability of levetiracetam versus phenytoin after supratentorial neurosurgery. Neurology 71:665-669, 2008

36. Moots PL, Maciunas RJ, Eisert DR, Parker RA, Laporte K, Abou-Khalil B: The course of seizure disorders in patients with malignant gliomas. Arch Neurol 52:717-724, 1995

37. North JB, Penhall RK, Hanieh A, Frewin DB, Taylor WB: Phenytoin and postoperative epilepsy. A double-blind study. J Neurosurg 58:672-677, 1983

38. Nossek E, Matot I, Shahar T, Barzilai O, Rapoport Y, Gonen $\mathrm{T}$, et al: Intraoperative seizures during awake craniotomy: incidence and consequences: analysis of 477 patients. Neurosurgery 73:135-140, 2013

39. Rosenbaum S: The Patient Protection and Affordable Care Act and the future of child health policy. Acad Pediatr 12:363-364, 2012

40. Rossetti AO, Stupp R: Epilepsy in brain tumor patients. Curr Opin Neurol 23:603-609, 2010

41. Siomin V, Angelov L, Li L, Vogelbaum MA: Results of a survey of neurosurgical practice patterns regarding the prophylactic use of anti-epilepsy drugs in patients with brain tumors. J Neurooncol 74:211-215, 2005

42. Szelényi A, Bello L, Duffau H, Fava E, Feigl GC, Galanda $\mathrm{M}$, et al: Intraoperative electrical stimulation in awake craniotomy: methodological aspects of current practice. Neurosurg Focus 28(2):E7, 2010

43. Temkin NR: Antiepileptogenesis and seizure prevention trials with antiepileptic drugs: meta-analysis of controlled trials. Epilepsia 42:515-524, 2001

44. van Breemen MS, Rijsman RM, Taphoorn MJ, Walchenbach $\mathrm{R}$, Zwinkels H, Vecht CJ: Efficacy of anti-epileptic drugs in patients with gliomas and seizures. J Neurol 256:1519-1526, 2009

45. Vecht CJ, van Breemen M: Optimizing therapy of seizures in patients with brain tumors. Neurology 67 (12 Suppl 4):S10S13, 2006

46. Wen PY, Marks PW: Medical management of patients with brain tumors. Curr Opin Oncol 14:299-307, 2002

47. Woo PY, Chan DT, Chan KY, Wong WK, Po YC, Kwok JC, et al: Risk factors for seizures and antiepileptic drugassociated adverse effects in high-grade glioma patients: A multicentre, retrospective study in Hong Kong. Surg Pract 19:2-8, 2015

48. Wu AS, Trinh VT, Suki D, Graham S, Forman A, Weinberg JS, et al: A prospective randomized trial of perioperative seizure prophylaxis in patients with intraparenchymal brain tumors. J Neurosurg 118:873-883, 2013

49. Yap KY, Chui WK, Chan A: Drug interactions between chemotherapeutic regimens and antiepileptics. Clin Ther 30:1385-1407, 2008

50. Zachenhofer I, Donat M, Oberndorfer S, Roessler K: Perioperative levetiracetam for prevention of seizures in supratentorial brain tumor surgery. J Neurooncol 101:101-106, 2011

51. Zeng TF, An DM, Li JM, Li YH, Chen L, Hong Z, et al: Evaluation of different antiepileptic drug strategies in medically refractory epilepsy patients following epilepsy surgery. Epilepsy Res 101:14-21, 2012

\section{Disclosures}

The authors report no conflict of interest concerning the materials or methods used in this study or the findings specified in this paper.

\section{Author Contributions}

Conception and design: all authors. Acquisition of data: Eseonu, Eguia, Garcia. Analysis and interpretation of data: QuiñonesHinojosa, Eseonu, Eguia, Kaplan. Drafting the article: QuiñonesHinojosa, Eseonu, Eguia. Critically revising the article: QuiñonesHinojosa, Eseonu, Kaplan. Reviewed submitted version of manuscript: all authors. Approved the final version of the manuscript on behalf of all authors: Quiñones-Hinojosa. Statistical analysis: Eseonu, Garcia. Study supervision: Quiñones-Hinojosa, Eseonu.

\section{Correspondence}

Alfredo Quiñones-Hinojosa, Department of Neurologic Surgery, Brain Tumor Stem Cell Laboratory, Mayo Clinic, 4500 San Pablo Rd. S, Jacksonville, FL 32224. email: quinones@mayo.edu. 